\title{
Discovery of a potent apo-IDO1 inhibitor for cancer immunotherapy
}

\author{
Wen $\mathrm{Liu}^{1}$, Yi Zou ${ }^{2}$, Kaiming $\mathrm{Li}^{1}$, Shushan $\mathrm{Ge}^{2}$, Haiqing Zhong ${ }^{1}$, Yuanyuna Wang ${ }^{3}$, Yue \\ $\mathrm{Hu}^{1}$, Yisheng $\mathrm{Lai}^{1}$, Xianchi Dong ${ }^{1}$, Wenjie Guo ${ }^{1}$, and Qiang $\mathrm{Xu}^{1}$ \\ ${ }^{1}$ Nanjing University \\ ${ }^{2}$ China Pharmaceutical University \\ ${ }^{3}$ Nanjing Medical University
}

August 28, 2020

\begin{abstract}
BACKGROUND AND PURPOSE Pharmacological inhibition of indoleamine-2,3-dioxygenase 1 activity is now considered to be a potential therapeutic tool for cancer therapy. However, the anti-cancer efficacy may be the biggest obstacle for the clinical application of current IDO1 inhibitors. EXPERIMENTAL APPROACHES HeLa cell-based IDO1/Kyn assay as well as recombinant IDO1 activity assay were used to determine the IDO1 enzyme activity. Interaction was examined by UV-visible spectra, isothermal titration calorimetry assay, cellular thermal shift assay and co-crystallization. Mouse colon cancer CT26 syngeneic model and azoxymethane/dextran sulfate sodium induced colon carcinogenesis model were employed to confirm the anti-tumor effect in vivo. KEY RESULTS B37 effectively and specifically inhibited IDO1 by targeting its heme-free conformation (apo-IDO1). By competing with heme for binding to apo-IDO1, B37 potently inhibited IDO1 activity with IC50 for 22 pM in the HeLa cell based assay. X-ray co-crystal structures of the inhibitor-enzyme complexes showed that unlike the hIDO1BMS-986205 complex, the B37-hIDO1 complex displayed stronger hydrophobic interactions, which enhanced its binding affinity measured with ITC. Accordingly, stronger non-covalent interactions including $\pi$ stacking and hydrogen bonds formed between B37 and apo-hIDO1 underlay the enthalpy-driven force for B37 to bind the enzyme. This binding model endowed B37 potent anti-tumor efficacy in mouse colon cancer CT26 syngeneic model and azoxymethane/dextran sulfate sodium induced colon carcinogenesis model by activating the host's immune system. Moreover, the combination of B37 with a VEGFR2 inhibitor apatinib synergistically inhibited tumor growth. CONCLUSIONS AND IMPLICATIONS These results revealed that B37 may serve as a candidate for apo-IDO1 inhibition mediated immunotherapy.
\end{abstract}

\section{Discovery of a potent apo-IDO1 inhibitor for cancer immunotherapy}

Wen Liu ${ }^{1,4}$, Yi Zou ${ }^{2,4}$, Kaiming $\mathrm{Li}^{1}{ }^{1}{ }^{4}$, Shushan Ge ${ }^{2}$, Haiqing Zhong ${ }^{1}$, Yuanyuan Wang ${ }^{3}$, Yue $\mathrm{Hu}^{1}$, Yisheng Lai ${ }^{2, *}$, Xianchi Dong ${ }^{1, *}$, Wenjie Guo ${ }^{1, *}$, Qiang $\mathrm{Xu}^{1, *}$

${ }^{1}$ State Key Laboratory of Pharmaceutical Biotechnology, School of Life Sciences, Nanjing University, Nanjing 210093, PR China

${ }^{2}$ State Key Laboratory of Natural Medicines, Jiangsu Key Laboratory of Drug Discovery for Metabolic Diseases, Center of Drug Discovery, China Pharmaceutical University, Nanjing 210009, PR China

${ }^{3}$ Department of Oncology, The First Affiliated Hospital of Nanjing Medical University, Nanjing, China

${ }^{4}$ Wen Liu, Yi Zou and Kaiming Li contributed equally to this work.

* Corresponding to

Prof Qiang Xu, molpharm@163.com

Prof Xianchi Dong, xianchidong@nju.edu.cn 
Dr. Wenjie Guo, guowj@nju.edu.cn

Prof Yisheng Lai,yslai@cpu.edu.cn

Running title: Apo-IDO1 inhibitor for cancer immunotherapy

Word counts: 8536

\section{Acknowledgments}

This work was supported by grants from the National Natural Science Foundation of China (81922067, 21937005, 21772233, 81903620), Six Talents Peaks in Jiangsu Province (YY-004). Natural Science Foundation of Jiangsu Province (BK20190306). Fundamental Research Funds for the Central Universities (14380114). Technology innovation fund of Nanjing University (14913413).

We thank Prof Zhao-Qiu Wu from China Pharmaceutical University for sharing the IDO1 knockout mice.

\section{Declare conflict of interests}

The authors declare no competing financial interest.

\section{BACKGROUND AND PURPOSE}

Pharmacological inhibition of indoleamine-2,3-dioxygenase 1 activity is now considered to be a potential therapeutic tool for cancer therapy. However, the anti-cancer efficacy may be the biggest obstacle for the clinical application of current IDO1 inhibitors.

\section{EXPERIMENTAL APPROACHES}

HeLa cell-based IDO1/Kyn assay as well as recombinant IDO1 activity assay were used to determine the IDO1 enzyme activity. Interaction was examined by UV-visible spectra, isothermal titration calorimetry assay, cellular thermal shift assay and co-crystallization. Mouse colon cancer CT26 syngeneic model and azoxymethane/dextran sulfate sodium induced colon carcinogenesis model were employed to confirm the anti-tumor effect in vivo .

\section{KEY RESULTS}

B37 effectively and specifically inhibited IDO1 by targeting its heme-free conformation (apo-IDO1). By competing with heme for binding to apo-IDO1, B37 potently inhibited IDO1 activity with $\mathrm{IC}_{50}$ for $22 \mathrm{pM}$ in the HeLa cell based assay. X-ray co-crystal structures of the inhibitor-enzyme complexes showed that unlike the hIDO1-BMS-986205 complex, the B37-hIDO1 complex displayed stronger hydrophobic interactions, which enhanced its binding affinity measured with ITC. Accordingly, stronger non-covalent interactions including $\pi$ stacking and hydrogen bonds formed between B37 and apo-hIDO1 underlay the enthalpy-driven force for B37 to bind the enzyme. This binding model endowed B37 potent anti-tumor efficacy in mouse colon cancer CT26 syngeneic model and azoxymethane/dextran sulfate sodium induced colon carcinogenesis model by activating the host's immune system. Moreover, the combination of B37 with a VEGFR2 inhibitor apatinib synergistically inhibited tumor growth.

\section{CONCLUSIONS AND IMPLICATIONS}

These results revealed that B37 may serve as a candidate for apo-IDO1 inhibition mediated immunotherapy.

Keywords: Apo-IDO1, heme, T cell, cancer immunotherapy, co-crystal

\section{Introduction}

Cancer immunotherapy, the science of mobilizing the immune system to kill cancer, has now taken center stage in mainstream oncology (Demaria et al., 2019; Kelly, 2018; Mezrich et al., 2010; Orabona et al., 2018). Cancer immunotherapy including immune checkpoint inhibitors such as blocking antibodies against cytotoxic T lymphocyte-associated antigen-4 (CTLA-4) and programmed cell death protein 1/programmed cell death ligand 1 (PD-1/PD-L1) pathway as well as chimeric antigen receptor (CAR) $\mathrm{T}$ cells, are approved by the 
U.S. Food and Drug Administration (FDA) and used in the clinical as main therapeutics for several types of cancers (Abu-Shawer et al., 2019; Munro, 2019). Although of unprecedented efficacy and relatively lower toxicity which reflects higher safety by immunotherapy, it remains unclear why only a subset of individuals responds to treatment and how to better achieve sustained remissions. Much of the effort were made by scientists and industry companies to improve the cancer immunotherapy cheaper, faster and better for lifesaving.

Indoleamine 2,3-dioxygenase 1 (IDO1) is an intracellular heme-based dioxygenase that catalyzes the first and rate-limiting step of the kynurenine pathway of tryptophan metabolism, which leads to the depletion of local tryptophan and accumulation of kynurenines and their derivatives (Platten et al., 2019). By activating $\mathrm{T}$ regulatory cells (Treg) and myeloid-derived suppressor cells (MDSC), suppressing the functions of effector T (Teff) and natural killer (NK) cells, and promoting neovascularization of solid tumor, this enzyme exerts important immunosuppressive functions including influencing the pathology of autoimmune diseases and, in particular, cancer immune tolerance (Cervenka et al., 2017; Cheong et al., 2017). Accordingly, pharmacological inhibition of the IDO1 activity is currently being explored for cancer therapy (Liu et al., 2018a).

So far, most reported IDO1 inhibitors are designed to act as competitive inhibitors either by mimicking the substrate tryptophan or by binding to the heme cofactor in the tryptophan binding pocket, such as NLG919, epacadostat (Rohrig et al., 2019). Regrettably, epacadostat failed in a large trial in combination with Merck's PD-1 inhibitor keytruda (pembrolizumab) in 2018, leading to obliterate enthusiasm for what was previously one of the hottest targets in immuno-oncology. Even so, considering the strong rationale for IDO1 inhibition and the discordant results between early- and late-stage clinical developments with epacadostat, other IDO1 inhibitors with different pharmacologic characteristics are still being tested under many IDO1-related preclinical and clinical trials.

Unlike NLG919 and epacadostat, BMS-986205 is a best-in-class IDO1 inhibitor with a unique mechanism, which irreversibly binds IDO1 in its apo form (Pham et al., 2018). X-ray crystal structures of the inhibitorenzyme complexes show that heme is displaced from the enzyme and blocked from rebinding by this kind of compounds. And what's more, crystal structures of hIDO1-BMS complex defined the complete binding trajectory of linrodostat to IDO1 (Pham \& Yeh, 2018). As heme lability is incredibly important to posttranslational regulation of IDO1, apo-IDO1 can be served as a unique target for inhibition. Thus, inhibitors in possession of this novel mechanism draw much attention and several candidates are currently under various stages of clinical investigation.

In the present study, the activity and mechanism of a potent $1 H$-pyrrole-2-carboxylic acid derivative (B37) targeting apo-IDO1 was identified. The co-crystal structure of IDO1-B37 revealed that the $1 H$-pyrrole-2carboxylic acid moiety of compound B37 interacted with His346, which was dispensable for the compound competing with heme binding to apo-IDO1. More in vitro analyses indicated that B37 strongly bound IDO1 by its apo-form while biological assessmentsin vivo demonstrated potent anticancer efficacy of B37 through reversing IDO1-mediated immunosuppression.

\section{Material and methods}

\section{Reagents}

Antibodies against PCNA (sc-56, RRID:AB_628110), and Actin (sc-130065, RRID:AB_1249316) were obtained from Santa Cruz Biotechnology (Santa Cruz, CA). CD4-FITC (11-0048-42, RRID:AB_1633390), CD8FITC (11-0084-82, RRID:AB_2572436), FOXP3-PE (12-4774-41, RRID:AB_10698014) and IFN- $\gamma$-PE (127311-81, RRID:AB_466192) were purchased from Thermofisher scientific (San Diego, CA). TUNEL BrightGreen Apoptosis Detection Kit (A112) was purchased from Vazyme Biotech Co.,Ltd (Nanjing, China). Streptavidin-HRP and DAB substrate were purchased from Genentech Company (Shanghai, China). The GTVision $^{\mathrm{TM}}$ anti-mouse/anti-rabbit Immunohistochemical Analysis Kit (GK500705) was purchased from GeneTech Company (Shanghai, China). Azoxymethane (AOM, A5486), were purchased from Sigma-Aldrich. Dextran sulfate sodium (DSS, 36-50 Kd, 0216011080) was purchased from MP Biomeicals. Chemical com- 
pounds B37 (MW: 245; Fig. 1a) was synthesized at the Department of Medicinal Chemistry, School of Pharmacy, China Pharmaceutical University, and the purity was no less than 99\%. Epacadostat and BMS986205 was purchased from Selleck. Stock solutions and prepared in DMSO for use in cell based assays. All the other chemicals were of high purity from commercial sources.

\section{Cell culture}

Human cervical carcinoma (HeLa) cells, mouse colon carcinoma (CT26) cells and Lewis lung cancer (LLC) cells were purchased from the Shanghai Institute of Cell Biology (Shanghai, China). Cells were maintained in DMEM medium supplemented with $10 \%$ (v/v) heat-inactivated fetal bovine serum and antibiotics (100 $\mathrm{U} / \mathrm{mL}$ penicillin and $100 \mathrm{U} / \mathrm{mL}$ streptomycin) at 37 in a humidified atmosphere of $5 \% \mathrm{CO}_{2}$ (Thermo Fisher Scientific, MA, USA).

Determination of inhibitory activity in HeLa cell-based IDO1/Kyn assay

HeLa cells were seeded in 96 -well culture plates at a density of $5 \times 10^{3}$ per well. On the next day, human IFN$\gamma(100 \mathrm{ng} / \mathrm{mL})$ and compounds in a total volume of $200 \mu \mathrm{L}$ culture medium containing $15 \mu \mathrm{g} / \mathrm{mL}$ of Ltryptophan were added to the cells. After incubation for 24 hours, $140 \mu \mathrm{L}$ of the supernatant was mixed with $10 \mu \mathrm{L}$ of $6.1 \mathrm{~N}$ trichloroacetic acid and the mixture was incubated for $30 \mathrm{~min}$ at $50{ }^{\circ} \mathrm{C}$. The reaction

mixture was then centrifuged for 10 minutes at $4000 \mathrm{rpm}$ to remove sediments. $100 \mu \mathrm{l}$ of the supernatant was mixed with $100 \mu \mathrm{l}$ of $2 \%$ (w/v) p-dimethylaminobenzaldehyde in acetic acid and measured at $480 \mathrm{~nm}$. The initial wells containing the cells in the remaining volume of $50 \mu \mathrm{l}$ were used to estimate cell viability in a classical MTT assay. To that end, $50 \mu \mathrm{l}$ of culture medium (Iscove medium with $10 \%$ FCS and amino acids) were added to the wells together with $20 \mu \mathrm{l} 4 \mathrm{mg} / \mathrm{mL}$ of MTT. After $4 \mathrm{~h}$ of incubation at 37, $200 \mu \mathrm{l}$ of DMSO were added to dissolve the crystals of formazan blue and the absorbance at $570 \mathrm{~nm}$ was measured after overnight incubation at 37 . Graphs of inhibition curves with $\mathrm{IC}_{50}$ values were generated using Prism 7.0.

Protein expression and purification

The cDNA of human IDO1 (hIDO1), synthesized by GenScript, was cloned into pET28a vectors containing a thrombin-cleavable N-terminal $6 \times$ His-tag. As such, after thrombin cleavage, three linker amino acids (GSH) remained at the $\mathrm{N}$ terminus of full-length hIDO1 protein. The construct was confirmed by DNA sequencing before being transformed intoEscherichia coli BL21 (DE3) cells, which were then cultured overnight on a LB agar plate supplemented with kanamycin. A single colony was isolated and inoculated into $10 \mathrm{~mL}$ of LB medium with kanamycin. After $6 \mathrm{~h}$ at $210 \mathrm{rpm}$ and 37 , the culture was expanded to $2 \mathrm{~L}$ in the same condition until the $\mathrm{OD}_{600 \mathrm{~nm}}$ reached 0.7 . Isopropyl $\beta$-D-1-thiogalactopyranoside (IPTG) was added to the final concentration of $0.5 \mathrm{mM}$. The culture was continued at lower temperature (30) for $6 \mathrm{~h}$.

To extract His-Tb-hIDO1 protein, red E. coli cells was sedimented at $4000 \mathrm{rpm}, 4$ for $20 \mathrm{~min}$. Washed with Buffer A (50 mM K $\mathrm{PO}_{4}, 0.3 \mathrm{M} \mathrm{KCl}, 5 \%$ glycerol, $0.1 \mathrm{mM}$ TCEP, $\left.\mathrm{pH} 7.1\right)$, the cells were resuspended in the same buffer and lysed in a homogenizer at 4 under 1200 bar. After centrifugation at 4, $14500 \mathrm{rpm}$ for 1 $\mathrm{h}$, the supernatant was incubated with $1 \mathrm{~mL}$ Ni-NTA agarose (QIAGEN) at 4 for $1 \mathrm{~h}$. Washed with Buffer A supplemented with $20 \mathrm{mM}$ imidazole, the Ni-NTA was subsequently eluted with Buffer A containing 250 $\mathrm{mM}$ imidazole. The dark red elution was dialyzed in $150 \mathrm{mM} \mathrm{KCl}, 1 \mathrm{mM}$ EDTA, $5 \%$ glycerol, $25 \mathrm{mM}$ $\mathrm{K}_{2} \mathrm{PO}_{4}(\mathrm{pH} 6.5)$ and concentrated by centrifugation. $15 \mathrm{U}$ of human $\alpha$-thrombin per $1 \mathrm{mg}$ of protein was added into His-Tb-hIDO1 for overnight cleavage at 4 . The mixture was applied to Ni-NTA again and flow through was collected. Complete His-tag cleavage was confirmed by SDS-PAGE and Western blotting. Concentrated to $2 \mathrm{~mL}$ by centrifugation, the sample was injected into a HiLoad 16/600 Superdex $200 \mathrm{pg}$ column (GE Healthcare Life Sciences) equilibrated with $50 \mathrm{mM}$ Tris (pH 7.4). Based on the absorbance at $280 \mathrm{~nm}$, purified hIDO1 protein was pooled after size-exclusion chromatography. hIDO1 protein was further concentrated to $20 \mathrm{mg} / \mathrm{mL}$ using Bradford protein assay. The ratio of $\mathrm{A}_{404 \mathrm{~nm}}$ to $\mathrm{A}_{280 \mathrm{~nm}}$ was 1.50 , suggesting the high heme occupancy. To obtain hIDO1 in its apo form, hIDO1 was incubated with $166 \mathrm{mM}$ $\mathrm{Na}$ 2-mercaptoethanesulfonate (MESNA) overnight at room temperature (Ortiz-Meoz et al., 2018a), then dialyzed in $50 \mathrm{mM}$ Tris (pH 7.4). Both apo and heme-bound hIDO1 was frozen in aliquots and stored at -80 
${ }^{\circ} \mathrm{C}$.

Recombinant IDO1 Activity Assay

Recombinant IDO1 activity at $25^{\circ} \mathrm{C}$ or $37^{\circ} \mathrm{C}$ was measured as previously described (Ortiz-Meoz et al., 2018b). Briefly, $100 \mathrm{nM}$ holo-IDO1 in $100 \mathrm{mM}$ potassium phosphate buffer (pH 7.2) plus $1 \mathrm{mM}$ CHAPS supplemented with $0.5 \%$ (v:v) catalase was added $(25 \mu \mathrm{l})$ to inhibitors in DMSO carrier ( $0.5 \mu \mathrm{l}$ DMSO volume) and allowed to incubate for the indicated time and temperature (varied). After the incubation, $4 \mathrm{mM}$ DTRP, $20 \mathrm{mM} \mathrm{L}-$ ascorbic acid and $1 \mu \mathrm{M}$ methylene blue in $100 \mathrm{mM}$ Potassium Phosphate buffer (pH 7.2) plus $1 \mathrm{mM}$ CHAPS were added to the reaction $(25 \mu \mathrm{l})$. The absorbance at $320 \mathrm{~nm}$ was measured. From those measurements, inhibition was calculated.

Crystallization, X-ray diffraction and structure determination

To obtain the cocrystals of hIDO1 protein and compound B37, hIDO1 protein in $50 \mathrm{mM}$ Tris (pH 7.4) was mixed with B37 dissolved in DMSO. Afterwards, the final mixture with $1.5 \mathrm{mM}$ of B37, $0.15 \mathrm{mM}$ of hIDO1 and $5 \%(\mathrm{v} / \mathrm{v})$ DMSO was incubated at $42{ }^{\circ} \mathrm{C}$ for $2 \mathrm{~h}$. After centrifugation at $4{ }^{\circ} \mathrm{C}, 15000 \mathrm{rpm}$ for $5 \mathrm{~min}$, the supernatant with a $\mathrm{A}_{404 \mathrm{~nm}}$ to $\mathrm{A}_{280 \mathrm{~nm}}$ ratio of 0.17 was separated with red precipitate. Dialyzed in $50 \mathrm{mM}$ Tris (pH 7.4) and concentrated to $13.5 \mathrm{mg} / \mathrm{mL}$ using Amicon Ultra centrifugal filters (Merck Millipore)., $0.7 \mu \mathrm{L}$ of the supernatant was mixed with $0.7 \mu \mathrm{L}$ of reservoir solution in sitting-drop trays at $4{ }^{\circ} \mathrm{C}$ for crystallization. Colorless crystals were obtained in the wells with reservoir solution containing $0.1 \mathrm{M} \mathrm{NaS}_{2} \mathrm{O}_{3}, 0.1 \mathrm{M}$ CAPS $(\mathrm{pH} 10.3)$ and $12 \%(\mathrm{w} / \mathrm{v})$ PEG 8000. Crystals were harvested and incubated in cryoprotectant composed of $80 \%$ reservoir solution and $20 \%$ glycerol before frozen in liquid nitrogen.

X-ray diffraction data for the cocrystals were collected at Shanghai Synchrotron Radiation Facility (SSRF) on beamline BL17U1. The data were indexed, integrated, and scaled using XDS (Otwinowski et al., 1997) and SCALA (Evans, 2006). The crystal structures were determined by molecular replacement with PHASER (McCoy et al., 2007) using the structure of hIDO1-trptophan complex (PDB code: 5WMU) as the initial searching model. The models were built with COOT(Emsley et al., 2004) and refined by PHENIX (Adams et al., 2002). The structural models were displayed using the program UCSF Chimera (Pettersen et al., 2004) and PyMOL (http://www.pymol.org/). BIOVIA Discovery Studio and LigPlot Plus (Laskowski et al., 2011) were employed to analyze protein-ligand interactions.

Isothermal titration calorimetry assay

The binding affinity between hIDO1 protein and compounds was measured by performing isothermal titration calorimetry (ITC) with a MicroCal iTC200 (GE Healthcare Life Sciences) instrument, which was thermoequilibrated at 25 or $37{ }^{\circ} \mathrm{C}$ with water in the reference cell. In all titration experiments, hIDO1 protein and compounds were freshly prepared in $50 \mathrm{mM}$ Tris (pH 7.4) with $5 \%$ (v/v) DMSO. Protein concentration was determined by the Bradford protein assay. Using an initial injection volume of $0.4 \mu \mathrm{L}$, hIDO1 protein $(240 \mu \mathrm{M})$ were titrated $(20 \times 2.0 \mu \mathrm{L})$ every 2 min into the stirred $(1000 \mathrm{rpm})$ sample cell containing $24 \mu \mathrm{M}$ compounds. Acquired raw heat evolutions were baseline-corrected and the integrated data excluding the first injection was fitted to a "One Set of Sites" model and analyzed in the Origin software package (version 5.0, MicroCal). The first injection was excluded from analysis in each assay. The fitted association constants $\left(K_{\mathrm{a}}\right)$ were used to decide the dissociation constants $\left(K_{\mathrm{d}}\right)$ based on the equation $K_{\mathrm{d}}=1 / K_{\mathrm{a}}$. The free energy $(\Delta G)$ was calculated using the relationship $\Delta G=-R T \ln K$ a, where $R$ and $T$ represent the gas constant and temperature respectively.

UV-visible spectra

Absorption spectra were recorded at $37{ }^{\circ} \mathrm{C}$ on a plate reader (Tecan Infinite $200 \mathrm{PRO}$ ) using 96-well plates with UV-transparent flat bottom. The reactions between hIDO1 and inhibitors were initiated by adding compound solutions to create the final mixture consisting of $75 \mu \mathrm{M}$ of compound, $7.5 \mu \mathrm{M}$ of ferric hIDO1 protein and $5 \%(\mathrm{v} / \mathrm{v})$ DMSO in $50 \mathrm{mM}$ Tris $(\mathrm{pH}$ 7.4). The control experiments were initiated by adding solutions of DMSO to reach the same final concentrations but without compounds. Blank spectra were measured with protein-free buffer in the same condition. The blank-subtracted spectra were analyzed and 
presented according to the manufacturer's instructions. The absorption spectra were recorded at regular intervals for over $2.5 \mathrm{~h}$.

\section{$T$ cells proliferation and cytokine assay}

CT26 cells were seeded in 6 -well culture plates at a density of $1 \times 10^{5}$ per well. On the next day, compounds containing $15 \mu \mathrm{g} / \mathrm{mL}$ of L-tryptophan in a total volume of $2 \mathrm{~mL}$ culture medium were added to the cells. 48 $\mathrm{h}$ later, culture supernatant was collected for $\mathrm{T}$ cell proliferation assay performed as follows. T lymphocytes prepared from splenocytes of BALB/c mice were resuspended with $100 \mu \mathrm{l}$ supernatant and $100 \mu \mathrm{l}$ RPMI 1640 containing 10\% FBS and $5 \mu \mathrm{g} / \mathrm{mL}$ ConA. $48 \mathrm{~h}$ later, supernatant was collected for ELISA assay for IFN- $\gamma$ while T cell proliferation was examined by MTT assay. To that end, an amount of $100 \mu \mathrm{l}$ of MTT (1 $\mu \mathrm{g} / \mathrm{ml}$ ) added to the wells. After $4 \mathrm{~h}$ of incubation at $37{ }^{\circ} \mathrm{C}$, an amount of $100 \mu \mathrm{l}$ of DMSO was added to dissolve the crystals of formazan blue and the absorbance was measured at $570 \mathrm{~nm}$. Supernatants collected from the co-culture system were subjected to ELISA analysis for IFN- $\gamma$ by using kits from Dakawe (Beijing, China).

Treg cells experiments

Treg cells were analyzed by using an eBioscience intracellular staining kit according to the manufacturer's instructions. After co-cultured with CT26 cells, T cells were collected. Surface staining was performed with a CD4-FITC and CD25-PE for 15 min at $4{ }^{\circ} \mathrm{C}$. After this, the cells were fixed and permeabilized with fixation buffer and permeabilization wash buffer. The intracellular staining was performed with FOXP3-APC for 20 min. The cells were then analyzed by flow cytometry analysis.

Animal model and treatment

Female BALB/c mice, C57BL/6 mice and nude mice, 6-8 weeks old, were purchased from the Model Animal Research Center of Nanjing University (Nanjing, China). Congenic IDO1 knockout mice on a C57BL/6 strain background were obtained from the Jackson Laboratory. They were maintained with free access to pellet food and water in plastic cages at $21 \pm 2{ }^{\circ} \mathrm{C}$ and kept on a $12 \mathrm{~h} \mathrm{light/dark} \mathrm{cycle.} \mathrm{Animal} \mathrm{welfare} \mathrm{and} \mathrm{experimental}$ procedures were performed in accordance with the Guide for the Care and Use of Laboratory Animals (National Institutes of Health, the United States) and the related ethical regulations of our university. All efforts were made to reduce the number of animals used and minimize animals' suffering. All efforts were made to minimize animals' suffering and to reduce the number of animals used. All studies involving animals are reported in accordance with the ARRIVE guidelines for reporting experiments involving animals (Kilkenny et al., 2010; McGrath et al., 2010).

Mouse colon cancer cells (CT26) were cultured and collected by centrifuged (1000 rpm, $5 \mathrm{~min}$ ) and washed twice with ice-cold PBS. Then cells were diluted to $1 \times 10^{7} / \mathrm{ml}$ and $1 \times 10^{6} \mathrm{CT} 26$ cells (in $0.1 \mathrm{ml}$ PBS) were injected subcutaneously into the right flanks of mice. All mice formed tumors three days after injection. Then mice were distributed into four groups $(\mathrm{n}=6)$ according to tumor volumes. B37 $(3,10 \mathrm{mg} / \mathrm{kg})$ were administered (i.g) to each group respectively every day since day $0.5-\mathrm{FU}$ (25 mg/kg) were administered (i.p) every two days. Tumor length and tumor width were measured with a vernier caliper every three days. Tumor volumes were measured and calculated using the equation volume $=\mathrm{a}^{*} \mathrm{~b}^{2} / 2$, where "a" is the maximal width and "b" is maximal orthogonal width. On the 17 th day, mice were weighed, euthanized, and tumors were removed and the weight were taken. Drugs were administered on days 1-15.

LPS stimulation of KP was performed in C57BL/6 mice as reported with some modifications (Yang et al., 2019). Briefly, Mice were injected i.p with Escherichia coli LPS (5 mg/kg) with a single oral dose of either the vehicle or B37 $(10 \mathrm{mg} / \mathrm{kg}$, ig) or EPA $(50 \mathrm{mg} / \mathrm{kg}$, ig), respectively. $24 \mathrm{~h}$ after LPS and compound administration, the mice were sacrificed and the blood was harvested. Na-Heparin whole blood was analyzed for tryptophan, and kynurenine using LC/MS.

Induction and treatment of colitis-associated cancer

Colitis-associated cancer model was induced as previous reported (Guo et al., 2014). To induce, mice were 
injected intraperitoneally (i.p.) with a single dose $(7.5 \mathrm{mg} / \mathrm{kg})$ of AOM followed by 3 cycles of $2.5 \%$ DSS given in the drinking water for $5 \mathrm{~d}$. B37 $(10 \mathrm{mg} / \mathrm{kg})$ was given i.g. daily from day 50 to day 80 . Mice were sacrificed on day 80 . The entire colon and rectum were processed for histopathological examination.

Real-time PCR

Total RNA from tissue samples was isolated using TRIzol reagent (Invitrogen, Carlsbad, CA, USA), according to the supplier's instructions. Real-time PCR was performed as follows as reported (Liu et al., 2018b). The primer sequences used in this study were as follows:

m- $\beta$-actin forward 5'-TGCTGTCCCTGTATGCCTCT-3';

reverse 5'-TTTGATGTCACGCACGATTT -3'.

m-ifn- $\gamma$ forward 5'-TGAGTATTGCCAAGTTTGAGGTCA-3';

reverse 5'-CGGCAACAGCTGGTGGAC-3'.

m-perforin 1 forward 5'-CCACTCCAAGGTAGCCAAT-3';

reverse 5'-GGAGATGAGCCTGTGGTAAG-3'.

m-cox2 forward 5'-CAGCCAGGCAGCAAATCC-3';

reverse 5'-ACATTCCCCACGGTTTTGAC-3'.

m-tnf- $\alpha$ forward 5'-CGAGTGACAAGCCTGTAGCCC-3';

reverse 5'-GTCTTTGAGATCCATGCCGTTG-3'.

m-granzyme b forward 5'-CTGCTAAAGCTGAAGAGTAAGG-3';

reverse 5'-ACCTCTTGTAGCGTGTTTGAG'.

m-fasl forward5'-CGTGAGTTCACCAACCAAAG-3';

reverse 5'-TGTGTCTTCCCATTCCAGAG-3'.

h-cytochrome p450 1a1, forword: 5'- TCTTCCTTCGTCCCCTTCAC-3',

reverse: 5'- TGGTTGATCTGCCACTGGTT-3';

h-ribosomal protein 113a, forword: 5'- CCTGGAGGAGAAGAGGAAAGAGA-3',

reverse: 5'- GAGGACCTCTGTGTATTTGTCAA-3'.

Immunohistochemistry (IHC) and immunofluorescence (IF)

Formalin-fixed paraffin-embedded tissue sections were used for IHC and IF as reported (Guo et al., 2014).

Western blot

Cells were collected and centrifuged at, washed by PBS, then the precipitation was lysised in $100 \mu$ l precooling lysate buffer containing $0.5 \%$ Triton X-100, Tris- $\mathrm{HCl}, \mathrm{NaCl}, 0.1 \mathrm{U} / \mathrm{ml}$ aprotinin and $1 \mathrm{mM}$ phenylmethylsulfonyl fluoride for $30 \mathrm{~min}$ on ice and centrifuged at for $10 \mathrm{~min}$. The supernatant was collected and followed by protein concentration determination using the BCA protein assay kit (Pierce, 23225). Western blotting were done as reported (Guo et al., 2013).

TUNEL assay

Paraffin-embedded tumor sections were stained with TUNEL-FITC (1:100) and then counter-stained with DAPI for 5 min. Images were acquired using a Confocal Laser-Scanning Microscope (Olympus FV1000).

Statistical analysis 
The data and statistical analysis comply with the recommendations on experimental design and analysis in pharmacology (Curtis et al., 2018). All experiments were randomized and blinded. Statistical analysis was performed with GraphPad Prism 7.0 software (San Diego, CA, USA). Student's t-test was used to determine the significance of difference between two groups. One-way ANOVA analysis followed by Dunnett's post hoc test was used to evaluate the differences between various experimental when there were more than two groups. Post tests were run only if $F$ achieved $\mathrm{P}<0.05$. The level of significance was set at a $P$ value of 0.05 .

\section{Results}

\section{B37 potently inhibited IDO1 enzyme activity}

B37, a $1 H$-pyrrole-2-carboxylic acid derivative, was discovered in our lab through fragment-based drug design. To determine the inhibitory effect of B37 (structure shown in Fig. 1a ) on IDO1 enzymatic activity, a cell-based kynurenine assay, where IDO1 expression was induced with interferon-gamma (IFN- $\gamma$ ) in HeLa cells, was employed. It has been reported that expression level of IDO1 but not IDO2 or tryptophan 2, 3dioxygenase (TDO2) was increased in the stimulated cells (Liu et al., 2010). We observed that B37 inhibited kynurenine production in the IDO1 cellular assay with a very low $\mathrm{IC}_{50}$ value of $22 \mathrm{pM}$ without affecting the protein expression of IDO1 in the stimulated cells (Fig. $1 \mathbf{b}$ and $1 \mathbf{d}$ ). Meanwhile, the $\mathrm{IC}_{50}$ value of epacadostat was $28.2 \mathrm{nM}$. At the meantime, B37 did not affect the proliferation of HeLa cells at dose as high as $1 \mu \mathrm{M}$ (Fig. s1). Moreover, B37 could not inhibit the TDO2 activity even at $300 \mathrm{nM}$ (data not shown). These results showed that B37 was a potent inhibitor of IDO1 in a cellular context.

Next, the blockade effect of B37 on overactivated kynurenine was investigated using LPS-treated mice. As shown in Fig. s2, the ryptophanconcentration in control mice at each sampling time was generally higher than that in modeling mice treated with LPS, which indicated that the control mice took more Trp than the modeling mice did because the mice were allowed ad libitum access to food and water during the experiment. In modeling mice, the kynurenine was stimulated involving the decreased tryptophan level, increased kynurenine level, and the enhanced kynurenine/tryptophan ratio. The effect of B37 on kynurenine was analyzed at 24 after dosing. It was found that B37 could significantly decrease the kynurenine level $24 \mathrm{~h}$ after dosing and yet not affect the tryptophan level and therefore markedly reversed the enhanced kynurenine/tryptophan ratio at $24 \mathrm{~h}$ after dosing.

In order to confirm the direct inhibition of B37 on IDO1, the purified recombinant hIDO1 protein based activity assay was set up as reported (Ortiz-Meoz et al., 2018b; Sono et al., 1980; Yue et al., 2017). As shown in Fig. 1c , incubation of epacadostat with hIDO1 at 25 and 37 got a similar $\mathrm{IC}_{50}$ value $(216 \mathrm{nM}$ at 25 and $133.6 \mathrm{nM}$ at 37 ). In contrast, $\mathrm{B} 37$ has an $\mathrm{IC}_{50}$ of $48.5 \mathrm{nM}$ for IDO1 activity at 37 while which was higher than $600 \mathrm{nM}$ at 25 . These data suggested that B37 might be an apo-IDO1 inhibitor.

\section{B37 bound to IDO1 and drove heme release}

Encouraged by the results that B37 lose the ability to inhibit IDO1 at 25 , we speculated that B37 could drive heme release from IDO1, similar with the reported mechanism of BMS-986205. To this end, the UV-visible spectra of IDO1 with or without B37 and BMS-986205 incubation were record the for over $2.5 \mathrm{~h}$ at $37^{\circ} \mathrm{C}$. The loss of absorbance at $404 \mathrm{~nm}$, which is the Soret peak of ferric IDO1, was observed, manifesting the loss of heme (Fig. s3a ). The gradual increase in the scattering in the UV window of the spectra indicated that IDO1 could be denatured by dimethyl sulfoxide (DMSO) slowly, while binding of the two inhibitors partly protected it from degradation (Fig. s3a ). In addition, the kinetics of heme release was measured by fitting the loss in absorbance at the Soret maxima to an exponential equation. By calculating and comparing the half-lives, B37 and BMS-986205 showed similar binding kinetics (half-life $=0.57$ and $0.45 \mathrm{~h}$, respectively) (Fig. s3b ). Taken together, the spectroscopic studies revealed that both of the compounds could promote heme release, as indicated by the decrease in the Soret band, with a kinetically similar activity.

In light of the above results, we next determined the IDO1 target engagement in both cellular and proteinbased assays. The cellular thermal shift assay (CETSA) in HeLa cells showed that B37 effectively bound 
and thermally stabilized IDO1 in cells (Fig. 2a and $2 \mathbf{b}$ ), confirming the IDO1 engagement of B37 in a cellular context. Then, we performed quantitative isothermal titration calorimetry (ITC) experiment to test whether B37 directly binds to hIDO1 protein for inhibition. In coincidence with the results from recombinant hIDO1 enzymatic inhibition assay, the binding of B37 or BMS-986205 to IDO1 was undetectable at 25 but it was observed at 37 . B37 directly interacted with IDO1 protein with a dissociation constant $\left(K_{\mathrm{d}}\right)$ of $625 \mathrm{nM}$, which showed a quite stronger binding than BMS-986205 did with a $K_{\text {d }}$ value of $3086 \mathrm{nM}$ (Fig. 2c ). Additionally, the binding signatures for the two compounds suggested the divergence of interaction driving forces. The binding of B37 to IDO1 was enthalpy-driven while that of BMS-986205 was entropydriven characteristic. These thermodynamic results implied that targeting of hIDO1 by the compounds was mechanistically different, which might be explained by structural study.

\section{Distinct bonding networks different from BMS-986205 contributed to the potency of B37}

Having identified compounds B37 with superior biochemical profiles, we were able to crystallize the hIDO1B37 complex and refined its structure to a resolution of 3.14 A (Table s1) to understand the structural basis of binding. Strong electron density associated with B37 and adjacent water molecules were evident in the binding pocket (Fig. s4). Compared to the structure of holo-IDO1 (PDB code: 6AZU) (Nelp et al., 2018), B37 binding did not significantly alter the overall structure of IDO1 (RMSD $=0.685)$. The major structural rearrangement introduced by B37 binding was the shift of the region between G261 and Q271, an event previously observed as the result of the binding of substrate tryptophan or its analogues (Lewis-Ballester et al., 2017a; Prendergast et al., 2017). In particular, the heme-coordinating residue A264 was perturbed most significantly (RMSD measured on $\mathrm{C} \alpha=4.2$ ) upon B37 binding. Similar to reported compounds BMS978587 and BMS-986205, B37 and heme shared the similar cavity inside IDO1 (Fig. 3a-d ), confirming the hypothesis that B37 is a heme-competitive IDO1 inhibitor. Unlike the nearly planar heme molecule, B37 deeply extended into the "A" pocket located in the distal heme site with its halogenated phenyl moiety (Platten, Nollen, Rohrig, Fallarino \& Opitz, 2019; Röhrig et al., 2019).

Apart from the overall conformational changes, comprehensive analysis of dominating protein-ligand interactions presented detailed features of protein-ligand interactions, which may interpret the potency of B37. Both B37 and BMS-986205 displaced heme-coordinating A264 and were $\pi$-stacked with another heme-coordinating residue H346 (Fig. 3h ). However, compared to BMS-986205, B37 processed more extensive non-covalent interactions. On the one hand, the two halogen bonds formed with S167 and C129, and one hydrogen bond formed with H346 provided B37 with additional potency (Fig. 3a and3c ). On the other hand, the cyclohexane and isobutane moiety of B37 formed extensive hydrophobic interactions with surrounding residues including V166, I217, V350 and I354, while the hydrophobic interactions between BMS-986205 and apo-IDO1 are weaker (Fig. $3 \mathbf{e}$ and $3 \mathbf{g}$ ). Taken together, these interactions underlay the stronger binding affinity of B37 over BMS-986205.

Although B37 and BMS-978587 occupy a similar position (Fig. 3aand 3b ), unique interactions mediated by B37 were clearly identified by the co-crystal structure (Fig. 3e and $3 \mathbf{f}$ ). The $\mathrm{Cl}$ atoms of B37 were halogenbonded with the sidechains of C129. This halogen bonding interaction, absent in other heme-displacing IDO1 inhibitors, might enhance the potency of B37. In addition, extensive $\pi$-stacking interactions between B37 and sidechains of F163 (face-to-face) and Y126 (edge-to-face) also stabilized the anchoring of the halogenated phenyl moiety in "A" pocket. Furthermore, the unique sulfur- $\pi$ interaction with the divalent sulfur atom of C129 might further contribute to the activity of B37.

\section{B37 inhibited tumor growth in immunocompetent mice}

B37, with its favorable in vitro pharmacodynamics properties both at molecular and cellular levels, was further progressed into in vivo preliminary pharmacokinetic studies at an intravenous dose of $2 \mathrm{mg} / \mathrm{kg}$ and at an oral dose of $10 \mathrm{mg} / \mathrm{kg}$ in mice. As shown in Table s1, B37 exhibits a moderate plasma duration (MRT), a good maximum drug concentration $\left(\mathrm{C}_{\max }\right)$, and acceptable half time $\left(\mathrm{T}_{1 / 2}\right)$. As well as a low-to-moderate bioavailability (F). Accordingly, these data suggest that B37 can be a potential candidate for cellular and 
animal studies.

Then, B37 was further evaluated in a mouse model of colon cancer in order to determine whether it can reverse immune tolerance and curtail tumor growth in vivo. Syngeneic tumors were generated by subcutaneous implantation of CT26 cells into BALB/c mice. B37 was administered by oral gavage at 3 and $10 \mathrm{mg} / \mathrm{kg}$ daily for 15 days. After 15 days of treatment, B37 significantly impeded the growth of tumor and reduced average tumor weight $(24.8 \%$ at $3 \mathrm{mg} / \mathrm{kg}$ and $36.2 \%$ at $10 \mathrm{mg} / \mathrm{kg}$ ) compared to the vehicle group (Fig. 4a-c), without significant body weight loss (Fig. s5). The traditional chemotherapy agent 5-Fluorouracil $(5-\mathrm{FU})(25 \mathrm{mg} / \mathrm{kg})$ was used as a reference compound and got an inhibition rate at $65.1 \%$. What's more, by comparing the effect of B37 with epacadostat, we found that B37 displayed a comparable anti-tumor efficacy with epacadostat but with a much lower dose (Fig. 4d-f , 40.5\% for B37 $10 \mathrm{mg} / \mathrm{kg}, 46.2 \%$ for epacadostat 50 $\mathrm{mg} / \mathrm{kg}$ ). In the experiment of survival analysis, B37 $10 \mathrm{mg} / \mathrm{kg}$ also showed a comparable survival promotion as epacadostat $50 \mathrm{mg} / \mathrm{kg}$ did (Fig. $4 \mathrm{~g}$ ).

The proliferation and survival of tumor cells affected by B37 treatment were then determined. Administration of B37 led to the change of morphological features including cell shrinkage and condensation and margination of nuclear chromatin (Fig. s6a ). Immunostaining of proliferating cell nuclear antigen (PCNA) in tumor tissue showed that the expression of PCNA was significantly decreased in the treated groups, suggesting that the proliferation of tumor cells was arrested after the treatment with B37 (Fig. s6b ). The results from terminal deoxynucleotidyl transferase dUTP nick end labeling (TUNEL) assay showed that there were more cell apoptosis occurring in the B37 treated group than those in the control group (Fig. s6c ).

Next analysis was performed to further investigate the exact state of $\mathrm{T}$ lymphocytes in tumor specimens. Immunohistochemistry (IHC) analysis demonstrated that the expression of Granzyme B as well as IFN- $\gamma$ expression was dramatically increased in the tumor specimens treated with B37, suggesting the elevated function of cytotoxic T lymphocytes (CTLs) (Fig. 5a and 5b ). Administration of B37 resulted in an increase of infiltrating CD8 T cells (Fig. 5c ). Meanwhile, less FOXP3 ${ }^{+} \mathrm{T}$ cells (Treg cells) were detected in spleen of B37 treated tumor-bearing mice (Fig. 5dand 5e ).

Based on these data, B37 was proven to be effective in suppressing the proliferation, inducing apoptosis of tumor cells and thus suppressing tumor outgrowth and keeping mice survive by activation of anti-tumor response.

\section{B37 inhibited colon cancer growth induced by AOM + DSS}

To further determine whether B37 could decrease the growth of colitis-associated carcinogenic cancer, we generated colitis-associated colonic tumorigenesis model by injecting mice with procarcinogenic AOM followed by 3 cycles of oral 2.5\% DSS administration. After tumor formation at day 50, B37 was administrated from day 50 to day 80 and the mice were sacrificed on day 80 (Fig. 6a ). B37 was well tolerated as all of the mice survived the treatment. Fewer and smaller tumors were observed in the B37-treated group (Fig. 6b ). The average number of tumors per mouse and tumor size was markedly reduced in the $10 \mathrm{mg} / \mathrm{kg}$ B37 treated group (Fig. 6c ). Correspondingly, the average tumor load, which represents the sum of the diameters of all tumors in a given mouse, was significantly decreased in the B37-treated group (Fig. 6c ). Moreover, H\&E and PCNA IHC stain showed that proliferation of tumor cells was hampered after B37 administration (Fig. $6 \mathbf{d}$ and $6 \mathbf{e})$. Finally, expression of IFN- $\gamma$ and Granzyme B was also proved to be elevated, indicating the promoted anti-tumor response in AOM + DSS model by B37 (Fig. s7). Together, these results indicate that B37 administration reduces colitis-associated tumorigenesis and growth in mice by activating host immune response.

\section{Colon cancer growth suppression by B37 depended on T cells and IDO1}

Furthermore, to confirm the on-target effect of the testing compoundin vivo, immunodeficient BALB/c nude mice and IDO1 knockout mice bearing CT26 tumors were treated by oral gavage with B37. As shown in Fig. 7a-c and Fig. s8, administration of B37 did not affect tumor growth in BALB/c nude mice, while traditional cytotoxic drug 5-FU dramatically suppressed tumor growth. These data implied that B37 inhibited tumor 
growth in mice by activating the functional immune system rather than cytotoxicity. Moreover, B37 showed a significant restraining against tumor growth in wild-type IDO1 (WT) mice, which was impaired in IDO1 knockout mice, in which the inhibition rate was decreased from $39.1 \%$ to $16.3 \%$ (Fig. 7d-f ). These data showed that B37 treatment did not suppress outgrowth of CT26 tumors in athymic nude mice or IDO1 knockout mice, further supporting the notion that T-cell mediated immunity and IDO1 targeting are essential for anti-tumor efficacy of B37.

\section{B37 combined with a VEGR2 inhibitor apatinib significantly inhibited the growth of trans- planted tumor in mice.}

To explore whether B37 plus apatinib has synergistically antineoplastic effect in vivo, CT26 mouse colon carcinoma cells was subcutaneously transplanted to establish xenograft murine model. Mice treated with B37 $(10 \mathrm{mg} / \mathrm{kg})$ and apatinib $(30 \mathrm{mg} / \mathrm{kg})$ alone had slower tumor growth and lower tumor weight (Fig. 8a and $8 \mathbf{b}, 30.2 \%$ reduction in tumor weight for apatinib, $34.1 \%$ reduction for B37). Combination therapy group showed remarkable effect in inhibition of tumor growth (55.6\%). In this case, no significant change in body weight was observed in the mice of each group during administration (Fig. 8c ), suggesting little side effects caused by combination of B37 and apatinib.

We further observed the effect of B37 plus apatinib on the proliferation of tumor cells in vivo . Histological analyses by H\&E staining showed that B37 plus apatinib strongly induced massive cell damage with nuclear shrinkage, sparse arrangement and fragmentation of tumor cells (Fig. s9a ). Consistent to H\&E stain, immunohistochemistry of PCNA showed that sharply decreased expression of PCNA protein in the tumor tissues of the combined treatment group compared with the single-drug administrated group (Fig. s9b ). In addition, TUNEL staining confirmed that B37 combining apatinib triggered extensive apoptosis in the tumor cells (Fig. s9c ). These results demonstrated that co-treatment of B37 and apatinib leads to elevated proliferation inhibition and apoptosis induction of tumor cells in vivo. Meanwhile, tumor vessels stained with PECAM-1 (CD31) for vascular endothelial cells was signigcanlty inhibited by apatinib while B37 showed minor effect on it (Fig. s10). we further analyzed the changes of immune cells and their functions in tumor tissues. There was a significant increase in $\mathrm{CD}^{+}$(Fig. s11a) and $\mathrm{CD} 8^{+} \mathrm{T}$ cells (Fig. s11b ) infiltration in tumor tissues treated with B37 alone and was augmented by apatinib. Both IFN- $\gamma$ and Granzyme B were further increased in combination treated group (Fig. s11c and s11d). These results suggest that co-therapy of B37 and apatinib can elevate T lymphocyte activation in tumors, resulted in a strong anti-tumor immune microenvironment.

\section{Discussion}

By using biochemical, cellular and animal studies, compound B37 was demonstrated to effectively bind and inhibit IDO1 activity, leading to significant tumor growth suppression by reversing IDO1 mediated immunosuppression.

As the most fully characterized enzyme in the kynurenine pathway, IDO1 play a crucial role in innate immunity regulation that acts by depleting tryptophan in both the inflammatory and tumor microenvironments. Based on its important role in cancer immune tolerance and development, targeting IDO1 is becoming an attractive approach for cancer therapy. Since the first description of indoximod ( $D$-1-MT, 1-methyl- $D$ tryptophan) as an IDO1 pathway inhibitor, an increasing number of IDO1 inhibitors are being tested in preclinical development or clinical trials (Cheong et al., 2018; Röhrig et al., 2015).

Once upon a time, epacadostat was deemed to be the most promising IDO1 inhibitor. However, with the failure of the phase III ECHO-301/ KEYNOTE-252 trial (epacadostat in combination with pembrolizumab in advanced melanoma) (Long et al., 2019), people started to re-consider the defects of epacadostat itself as well as the target property of IDO1. The presence of several polar functional groups made epacadostat not to be suggestive of a drug-like molecule (Yue et al., 2017). Epacadostat showed relatively modest inhibitory activities against kynurenine synthesis in a human IDO1 enzymatic assay $\left(\mathrm{IC}_{50}=72 \mathrm{nM}\right.$ as reported and $\mathrm{IC}_{50}=133.3 \mathrm{nM}$ in our study). The co-crystal structure of IDO1 with epacadostat revealed that epacadostat bound to holo-IDO1 by forming hexa-coordination with the heme iron (Lewis-Ballester et al., 2017b; Luo et 
al., 2018). Moreover, as tryptophan competitive inhibitors, epacadostat and NLG919 showed an unexpected activation of ligand-activated transcription factor aryl hydrocarbon receptor (AhR) (Moyer et al., 2017). AhR activation leads to the generation of immune-tolerant DCs and Treg cells, thus interfering with the ability of anti-tumor inhibition immune response after IDO1 inhibition (Gutiérrez-Vázquez et al., 2018; Shinde et al., 2018; Xue et al., 2018). Compared to epacadostat, compound B37 has higher potency and it did not promote the expression of AhR (Fig. s12). Moreover, $10 \mathrm{mg} / \mathrm{kg}$ B37 has the comparable tumor inhibition rate with $50 \mathrm{mg} / \mathrm{kg}$ epacadostat.

On the other hand, the failure of epacadostat drive scientists to explore new action mode on IDO1 and several best-in-class inhibitors are being developed. As IDO1 is a heme-containing enzyme, inhibitors which exclude the heme from the enzyme showed high potency such as BMS-986205, GSK5628 and a recently compound developed by DNA-Encoded Library Technology (Ortiz-Meoz et al., 2018b; Pham \& Yeh, 2018)'(Kazmierski et al., 2020). By competing with heme for binding to a heme-free conformation of IDO1, these kinds of inhibitors showed generally remarkable efficacy and suicide inhibition activity on IDO1. BMS-986205 is the most developed apo-IDO1 inhibitor with an $\mathrm{IC}_{50}$ of $1.7 \mathrm{nM}$ in the HeLa cell-based assay. Phase III clinical trials using BMS-986205 are being carried out, including neoadjuvant chemotherapy alone or with nivolumab with/without linrodostat mesylate (BMS-986205) for muscle-invasive bladder cancer (Sonpavde et al., 2020), suggesting that this new mechanism of IDO1 inhibition is promising for drug development. Accordingly, B37 drove heme release from IDO1 protein, bound to apo-IDO1, which demonstrated it to be an apo-IDO1 inhibitor.

As monotherapy by IDO1 inhibitors may not achieve fully regression of caner, the combination of an IDO1 inhibitor with other therapeutic agents such as immune checkpoint inhibitors or chemotherapy represents an alternative strategy in cancer immunotherapy (Ladomersky et al., 2018; Zhu et al., 2019). It has been reported that IDO1 plays a key role in promoting tumor neovascularization (Mondal et al., 2016; Pan et al., 2017), while VEGF/VEGFR pathway blockade was reported to play an important role in inhibiting Treg cells infiltration both peritumoral or tumoral (Terme et al., 2013). This evidence inspired us to examine the combination effect of B37 with VEGFR2 inhibitor. Apatinb, a specific inhibitor targeting VEGFR2 recognized in China, is reported to obviously prolong both the overall survival (OS) and the progression-free survival (PFS) of patients with progressive gastric cancer who have failed second-line treatment (Geng et al., 2015). Many clinical trials indicate that apatinib encourages anticancer activity in a variety of malignancies including advanced colorectal cancer (Chen et al., 2019; Geng \& Li, 2015; Hu et al., 2014; Scott et al., 2015). Tumor neovascularization by CD31 staining in tumor tissues showed that apatinib single-drug treatment obviously inhibited the growth of tumor vessels while B37 treatment also showed some effect but in a weak extent. Based this on-target effect of apatinib, the combination of B37 and apatinib resulted in significant tumor suppression by elevation of anti-tumor immune response.

\section{Conclusion}

In summary, compared with epacadostat, our compound possessed higher potent inhibitory effect on IDO1 via interacting with its apo form. This apo-IDO1 inhibitor with novel structural type possess stronger inhibition against transplanted CT26 tumor and AOM+DSS induced tumorigenesis at a relative lower dosage, which was proved to be dependent on T cells and IDO1. And for the first time, a good promising in the combination with apatinib by elevation of anti-tumor immune response was shown. Taken together, the data presented here suggest that B37 can be further developed as a potential immunotherapeutic agent used in combination with other drug for cancer treatment.

\section{References}

Abu-Shawer O, Bushnaq T, \& Abu-Shawer M (2019). Cancer Immunotherapy: An Updated Overview of Current Strategies and Therapeutic Agents. The Gulf journal of oncology 1: 76-82.

Adams PD, Grosse-Kunstleve RW, Hung LW, Ioerger TR, McCoy AJ, Moriarty NW, et al. (2002). PHENIX: building new software for automated crystallographic structure determination. Acta crystallographica Section D, Biological crystallography 58: 1948-1954. 
Cervenka I, Agudelo LZ, \& Ruas JL (2017). Kynurenines: Tryptophan's metabolites in exercise, inflammation, and mental health. Science 357.

Chen X, Qiu T, Zhu Y, Sun J, Li P, Wang B, et al. (2019). A Single-Arm, Phase II Study of Apatinib in Refractory Metastatic Colorectal Cancer. Oncologist 24: 883-e407.

Cheong JE, \& Sun L (2017). Targeting the IDO1/TDO2-KYN-AhR Pathway for Cancer Immunotherapy Challenges and Opportunities. Trends Pharmacol Sci.

Cheong JE, \& Sun L (2018). Targeting the IDO1/TDO2-KYN-AhR Pathway for Cancer Immunotherapy Challenges and Opportunities. Trends Pharmacol Sci 39: 307-325.

Curtis MJ, Alexander S, Cirino G, Docherty JR, George CH, Giembycz MA, et al. (2018). Experimental design and analysis and their reporting II: updated and simplified guidance for authors and peer reviewers. Br J Pharmacol 175: 987-993.

Demaria O, Cornen S, Daeron M, Morel Y, Medzhitov R, \& Vivier E (2019). Harnessing innate immunity in cancer therapy. Nature 574:45-56.

Emsley P, \& Cowtan K (2004). Coot: model-building tools for molecular graphics. Acta Crystallogr D Biol Crystallogr 60: 2126-2132.

Evans P (2006). Scaling and assessment of data quality. Acta crystallographica Section D, Biological crystallography $62: 72-82$.

Geng R, \& Li J (2015). Apatinib for the treatment of gastric cancer. Expert opinion on pharmacotherapy 16: $117-122$.

Guo W, Sun Y, Liu W, Wu X, Guo L, Cai P, et al. (2014). Small molecule-driven mitophagy-mediated NLRP3 inflammasome inhibition is responsible for the prevention of colitis-associated cancer. Autophagy 10: $972-985$.

Guo WJ, Zhang YM, Zhang L, Huang B, Tao FF, Chen W, et al.(2013). Novel monofunctional platinum (II) complex Mono-Pt induces apoptosis-independent autophagic cell death in human ovarian carcinoma cells, distinct from cisplatin. Autophagy 9: 996-1008.

Gutiérrez-Vázquez C, \& Quintana FJ (2018). Regulation of the Immune Response by the Aryl Hydrocarbon Receptor. Immunity 48: 19-33.

Hu X, Cao J, Hu W, Wu C, Pan Y, Cai L, et al. (2014). Multicenter phase II study of apatinib in non-triplenegative metastatic breast cancer. BMC cancer 14: 820.

Kazmierski WM, Xia B, Miller J, De la Rosa M, Favre D, Dunham RM, et al. (2020). DNA-Encoded Library Technology-Based Discovery, Lead Optimization, and Prodrug Strategy toward Structurally Unique Indoleamine 2,3-Dioxygenase-1 (IDO1) Inhibitors. J Med Chem 63:3552-3562.

Kelly PN (2018). The Cancer Immunotherapy Revolution. Science 359: 1344-1345.

Kilkenny C, Browne W, Cuthill IC, Emerson M, \& Altman DG (2010). Animal research: reporting in vivo experiments: the ARRIVE guidelines. Br J Pharmacol 160: 1577-1579.

Ladomersky E, Zhai L, Lenzen A, Lauing KL, Qian J, Scholtens DM, et al. (2018). IDO1 Inhibition Synergizes with Radiation and PD-1 Blockade to Durably Increase Survival Against Advanced Glioblastoma. Clin Cancer Res 24: 2559-2573.

Laskowski RA, \& Swindells MB (2011). LigPlot+: Multiple Ligand-Protein Interaction Diagrams for Drug Discovery. Journal of Chemical Information and Modeling 51: 2778-2786.

Lewis-Ballester A, Pham KN, Batabyal D, Karkashon S, Bonanno JB, Poulos TL, et al. (2017a). Structural insights into substrate and inhibitor binding sites in human indoleamine 2,3-dioxygenase 1 . Nature 
Communications 8: 1693 .

Lewis-Ballester A, Pham KN, Batabyal D, Karkashon S, Bonanno JB, Poulos TL, et al. (2017b). Structural insights into substrate and inhibitor binding sites in human indoleamine 2,3-dioxygenase 1. Nat Commun 8: 1693.

Liu M, Wang X, Wang L, Ma X, Gong Z, Zhang S, et al. (2018a). Targeting the IDO1 pathway in cancer: from bench to bedside. Journal of hematology \& oncology 11: 100.

Liu W, Wu TC, Hong DM, Hu Y, Fan T, Guo WJ, et al. (2018b). Carnosic acid enhances the anti-lung cancer effect of cisplatin by inhibiting myeloid-derived suppressor cells. Chinese journal of natural medicines 16: $907-915$.

Liu X, Shin N, Koblish HK, Yang G, Wang Q, Wang K, et al. (2010). Selective inhibition of IDO1 effectively regulates mediators of antitumor immunity. Blood 115: 3520-3530.

Long GV, Dummer R, Hamid O, Gajewski TF, Caglevic C, Dalle S, et al. (2019). Epacadostat plus pembrolizumab versus placebo plus pembrolizumab in patients with unresectable or metastatic melanoma (ECHO301/KEYNOTE-252): a phase 3, randomised, double-blind study. The Lancet Oncology 20: 1083-1097.

Luo S, Xu K, Xiang S, Chen J, Chen C, Guo C, et al. (2018). High-resolution structures of inhibitor complexes of human indoleamine 2,3-dioxygenase 1 in a new crystal form. Acta Crystallogr F Struct Biol Commun 74: 717-724.

McCoy AJ, Grosse-Kunstleve RW, Adams PD, Winn MD, Storoni LC, \& Read RJ (2007). Phaser crystallographic software. J Appl Crystallogr 40: 658-674.

McGrath JC, Drummond GB, McLachlan EM, Kilkenny C, \& Wainwright CL (2010). Guidelines for reporting experiments involving animals: the ARRIVE guidelines. Br J Pharmacol 160: 1573-1576.

Mezrich JD, Fechner JH, Zhang X, Johnson BP, Burlingham WJ, \& Bradfield CA (2010). An interaction between kynurenine and the aryl hydrocarbon receptor can generate regulatory T cells. J Immunol 185:31903198.

Mondal A, Smith C, DuHadaway JB, Sutanto-Ward E, Prendergast GC, Bravo-Nuevo A, et al. (2016). IDO1 is an Integral Mediator of Inflammatory Neovascularization. EBioMedicine 14: 74-82.

Moyer BJ, Rojas IY, Murray IA, Lee S, Hazlett HF, Perdew GH, et al. (2017). Indoleamine 2,3-dioxygenase 1 (IDO1) inhibitors activate the aryl hydrocarbon receptor. Toxicology and applied pharmacology 323: 74-80.

Munro N (2019). Immunology and Immunotherapy in Critical Care: An Overview. AACN advanced critical care 30: 113-125.

Nelp MT, Kates PA, Hunt JT, Newitt JA, Balog A, Maley D, et al.(2018). Immune-modulating enzyme indoleamine 2,3-dioxygenase is effectively inhibited by targeting its apo-form. Proceedings of the National Academy of Sciences 115: 3249-3254.

Orabona C, Mondanelli G, Puccetti P, \& Grohmann U (2018). Immune Checkpoint Molecules, Personalized Immunotherapy, and Autoimmune Diabetes. Trends in molecular medicine 24: 931-941.

Ortiz-Meoz R, Wang L, Matico R, Rutkowska A, la Rosa MD, Bedard S, et al. (2018a). Characterization of novel inhibition of indoleamine 2,3-dioxygenase by targeting its apo form. bioRxiv: 324947 .

Ortiz-Meoz R, Wang L, Matico R, Rutkowska A, la Rosa MD, Bedard S, et al. (2018b). Characterization of novel inhibition of indoleamine 2,3-dioxygenase by targeting its apo form. . BioRxiv:324947 Biochemistry.

Otwinowski Z, \& Minor W (1997). Processing of X-ray diffraction data collected in oscillation mode. Methods Enzymol 276: 307-326. 
Pan J, Yuan K, Peng S, Huang Y, Zhang Y, Hu Y, et al. (2017). Gene silencing of indoleamine 2,3-dioxygenase hinders tumor growth through angiogenesis inhibition. International journal of oncology 50: 2136-2144.

Pettersen EF, Goddard TD, Huang CC, Couch GS, Greenblatt DM, Meng EC, et al. (2004). UCSF Chimera - A visualization system for exploratory research and analysis. Journal of Computational Chemistry 25: 1605-1612.

Pham KN, \& Yeh SR (2018). Mapping the Binding Trajectory of a Suicide Inhibitor in Human Indoleamine 2,3-Dioxygenase 1. J Am Chem Soc 140: 14538-14541.

Platten M, Nollen EAA, Rohrig UF, Fallarino F, \& Opitz CA (2019). Tryptophan metabolism as a common therapeutic target in cancer, neurodegeneration and beyond. Nature reviews Drug discovery 18:379-401.

Prendergast GC, Malachowski WP, DuHadaway JB, \& Muller AJ (2017). Discovery of IDO1 Inhibitors: From Bench to Bedside. Cancer Research 77: 6795-6811.

Röhrig UF, Majjigapu SR, Vogel P, Zoete V, \& Michielin O (2015). Challenges in the Discovery of Indoleamine 2,3-Dioxygenase 1 (IDO1) Inhibitors. J Med Chem 58: 9421-9437.

Rohrig UF, Reynaud A, Majjigapu SR, Vogel P, Pojer F, \& Zoete V (2019). Inhibition Mechanisms of Indoleamine 2,3-Dioxygenase 1 (IDO1). J Med Chem 62: 8784-8795.

Röhrig UF, Reynaud A, Majjigapu SR, Vogel P, Pojer F, \& Zoete V (2019). Inhibition Mechanisms of Indoleamine 2,3-Dioxygenase 1 (IDO1). Journal of medicinal chemistry 62: 8784-8795.

Scott AJ, Messersmith WA, \& Jimeno A (2015). Apatinib: a promising oral antiangiogenic agent in the treatment of multiple solid tumors. Drugs of today (Barcelona, Spain : 1998) 51: 223-229.

Shinde R, \& McGaha TL (2018). The Aryl Hydrocarbon Receptor: Connecting Immunity to the Microenvironment. Trends Immunol 39: 1005-1020.

Sono M, Taniguchi T, Watanabe Y, \& Hayaishi O (1980). Indoleamine 2,3-dioxygenase. Equilibrium studies of the tryptophan binding to the ferric, ferrous, and CO-bound enzymes. The Journal of biological chemistry 255: $1339-1345$.

Sonpavde G, Necchi A, Gupta S, Steinberg GD, Gschwend JE, Van Der Heijden MS, et al. (2020). ENERGIZE: a Phase III study of neoadjuvant chemotherapy alone or with nivolumab with/without linrodostat mesylate for muscle-invasive bladder cancer. Future oncology (London, England) 16: 4359-4368.

Terme M, Pernot S, Marcheteau E, Sandoval F, Benhamouda N, Colussi O, et al. (2013). VEGFA-VEGFR pathway blockade inhibits tumor-induced regulatory T-cell proliferation in colorectal cancer. Cancer research 73: 539-549.

Xue P, Fu J, \& Zhou Y (2018). The Aryl Hydrocarbon Receptor and Tumor Immunity. Frontiers in immunology 9: 286.

Yang D, Zhang S, Fang X, Guo L, Hu N, Guo Z, et al. (2019). N-Benzyl/Aryl Substituted Tryptanthrin as Dual Inhibitors of Indoleamine 2,3-Dioxygenase and Tryptophan 2,3-Dioxygenase. J Med Chem.

Yue EW, Sparks R, Polam P, Modi D, Douty B, Wayland B, et al.(2017). INCB24360 (Epacadostat), a Highly Potent and Selective Indoleamine-2,3-dioxygenase 1 (IDO1) Inhibitor for Immuno-oncology. ACS Med Chem Lett 8: 486-491.

Zhu MMT, Dancsok AR, \& Nielsen TO (2019). Indoleamine Dioxygenase Inhibitors: Clinical Rationale and Current Development. Curr Oncol Rep 21: 2.

Figure legends

Fig. 1 B37 inhibited IDO1 activity. (a) Structure of compound B37. (b) HeLa cell based activity for B37 and epacadostat. (c) IDO1 protein based activity for B37 and epacadostat. (d) B37 did not alter expression 
of IDO. HeLa cells were treated with IFN- $\gamma$ with or without the inhibitors for $24 \mathrm{~h}$. Expression of IDO was analyzed by western blot.

Fig. 2 B37 bound apo-IDO1. (a) IFN- $\gamma$-treated HeLa cells were incubated with or without B37 (100 $\mathrm{nM}$ ) for $2 \mathrm{~h}$, then the cells were collected and subjected to CETSA assay. (b) IFN- $\gamma$-treated HeLa cells were incubated with or without indicated dose of B37 for $1 \mathrm{~h}$, then the cells were collected and subjected to CETSA assay at 55 .(c) Baseline-corrected isothermal titration calorimetry (ITC) measurements of the interaction between compounds and the enzyme. ITC was carried out to measure the affinity between ferric heme-bound hIDO1 and B37 or BMS-986205 at 37 . Both inhibitors bind hIDO1 with a stoichiometry approaching 1:1.

Fig. 3 Comparison of the binding modes among three IDO1 inhibitors and heme. (a-d) Enlarged view of the interactions between apo-IDO1 and four compounds in the same pocket. Interacting residues in the binding pocket are shown in sticks while water molecules are shown as red spheres. Hydrogen bonds are shown in black dashed lines.(e-h) Schematic diagrams of representative protein-ligand interactions formed with IDO1 on compound binding. IDO1 residues are shown in blue oval and water is in red circle. Hydrogen/halogen bonds, pi-pi stacking and pi-sulfur interactions are denoted as green, violet and orange dashed lines, respectively (a and e) B37 in this study. (b and f)BMS-978587 (PDB code: 6AZV).(c and g) BMS-986205 (PDB code: 6MQ6). (d and $\mathbf{h}$ ) heme in holo-IDO1 (PDB code: 6AZU).

Fig. 4 B37 inhibited tumor growth in immunocompetent mice. (a-f) $1 \times 10^{6}$ CT26 cells were transplanted subcutaneously into the armpit of the BALB/c mice. Three days after transplantation, mice were randomly allocated to vehicle control or treatment groups $(n=6)$. Drugs were administered on days 1-15.(a, d) Tumor volume. (b, e) After sacrifice, solid tumors were separated and weighed (c, f) . Data represent mean $\pm \mathrm{SEM}, \mathrm{n}=6,{ }^{* *} \mathrm{P}<0.01$ versus vehicle. ${ }^{*} P<0.05,{ }^{* *} P<0.01$ vs. vehicle. $(\mathrm{g}) 1 \times 10^{6} \mathrm{CT} 26$ cells were transplanted subcutaneously into the armpit of the BALB/c mice. Three days after transplantation, mice were randomly allocated to vehicle control or treatment groups $(n=7)$. Drugs were administered on days 1-20 as indicated in i . Survival of the mice were recorded and calculated. EPA: epacadostat.

Fig. 5 B37 treatment enhanced the anti-tumor immunity in xenograft tumors. Tumor sections were infused in formaldehyde solution for immune stain. (a) Expression of IFN- $\gamma$. (b)Expression of Granzyme B.(c) $\mathrm{CD}^{+} \mathrm{T}$ and $\mathrm{CD}^{+} \mathrm{T}$ cells in tumor tissue. (d, e)Spleenic $\mathrm{T}$ cell were collected and subjected to intracellular staining for IFN- $\gamma$ and FOXP3. Scale bar $50 \mu \mathrm{m}$.

Fig. 6 B37 inhibited tumor growth induced by AOM+DSS. Mice were injected i.p. with a single dose $(7.5 \mathrm{mg} / \mathrm{kg})$ of AOM followed by 3 cycles of $2.5 \%$ DSS given in the drinking water for $5 \mathrm{~d}$. B37 (10 $\mathrm{mg} / \mathrm{kg}$ ) was given i.g. daily from day 50 to day 80 . Mice were sacrificed on day 80.(a) Overview of the experimental design. (b) The inside of the colon was photographed. (c) Tumor diameter and distribution were measured. (d) colon tissues were fixed and stained with H\&E. (e) Tumor numbers were counted. The tumor load was determined by totaling the diameters of all tumors for a given animal. Values are mean \pm SEM of 6 mice/group. ${ }^{*} P<0.05,{ }^{* *} P<0.01$ vs. AOM + DSS group. Scale bar $50 \mu \mathrm{m}$.

Fig. 7 Colon cancer growth suppression by B37 depended on $\mathbf{T}$ cells and IDO1. (a-c) $1 \times$ $10^{6}$ CT26 cells were transplanted subcutaneously into the armpit of the BALB/c nude mice. Three days after transplantation, mice were randomly allocated to vehicle control or treatment groups $(\mathrm{n}=6)$. Drugs were administered on days 1-15. (a) Tumor volume were recorded. (b, c ) After sacrifice, solid tumors were separated and weighed. (d-e ) $1 \times 10^{6} \mathrm{MC} 38$ cells were transplanted subcutaneously into the armpit of the WT or IDO1 knockout mice (C57BL/6). Three days after transplantation, mice were randomly allocated to vehicle control or treatment groups $(\mathrm{n}=6)$. Drugs were administered on day 1-19.(a) Tumor volume were recorded. (b, c ) After sacrifice, solid tumors were separated and weighed. Data represent mean \pm SEM, $\mathrm{n}=6,{ }^{*} P<0.05,{ }^{* *} P<0.01$ vs. vehicle. Scale bar, $50 \mu \mathrm{m}$.

Fig. 8 B37 combined with Apatinib significantly inhibited the growth of transplanted tumor in mice. $1 \times 10^{6} \mathrm{CT} 26$ cells were transplanted subcutaneously into armpit of the BALB/c mice. Three days after transplanted, mice were randomly allocated to either control or treatment groups, with 6 mice 
per group. Drugs were given as indicated in Materials and methods. Body weight and tumor volumes were measured everyday $(\mathbf{a}, \mathbf{b})$. After sacrificed, solid tumors were separated, photographed and weighted $(\mathbf{c}, \mathbf{d}$ ). Data are presented as mean \pm SEM of 6 mice per group. ${ }^{*} P<0.05,{ }^{* *} P<0.01$ vs. as indicated.

a

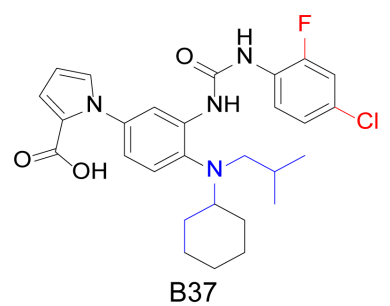

b

HeLa cell based activity

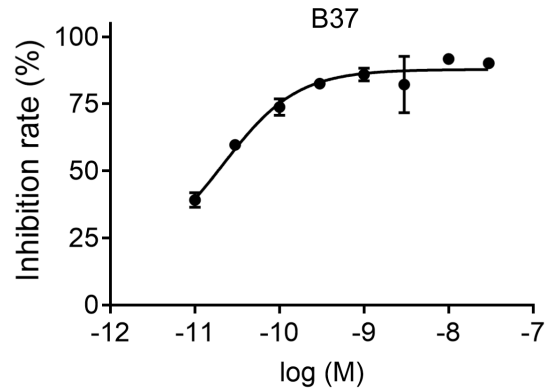

C

IDO1 protein based activity
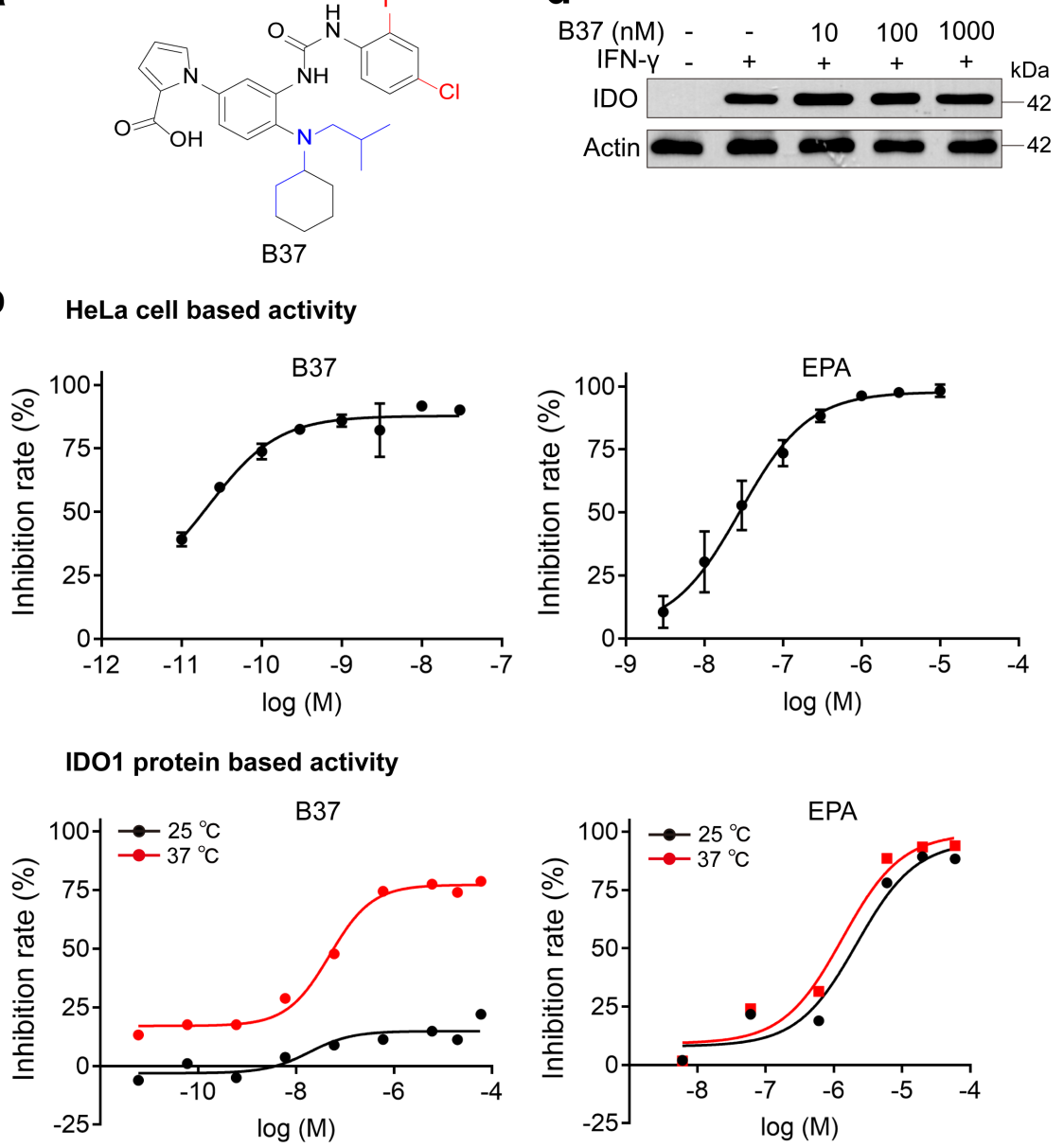

a

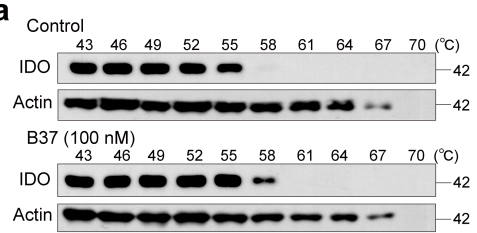

b

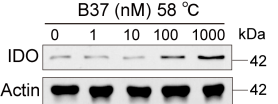

C

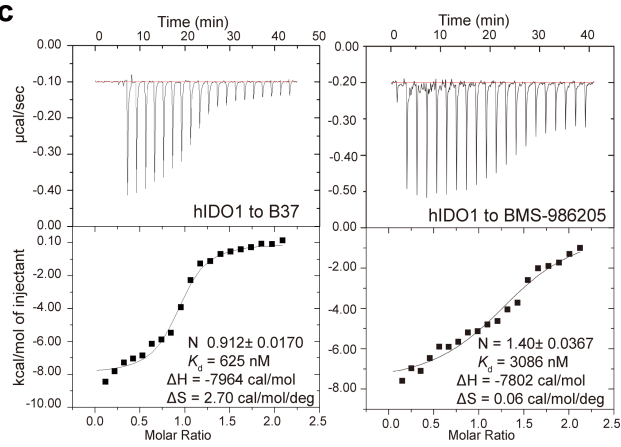


a

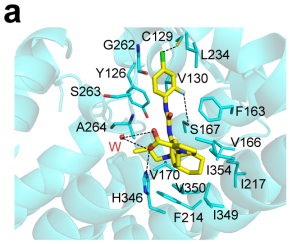

e

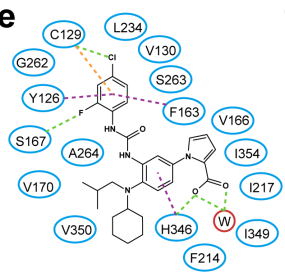

b

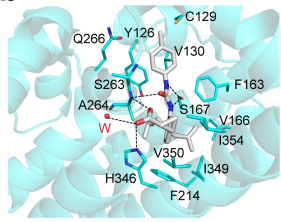

f (1126) (11220)

(1130) (1) (5263) Fi163

(S167) ... A1

(1349)

(v166) $\mathrm{F} 214$
C

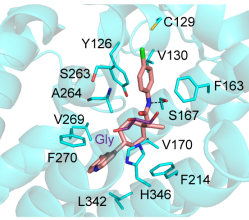

d

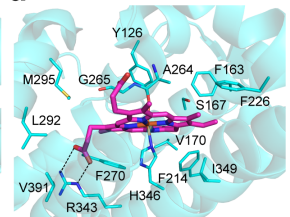

a

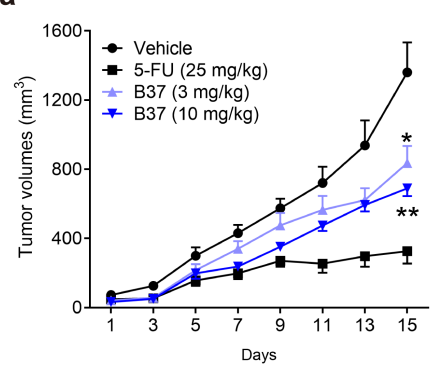

d

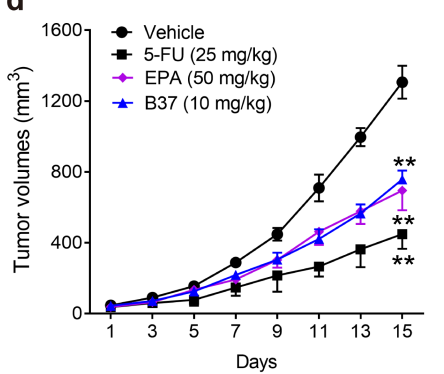

b
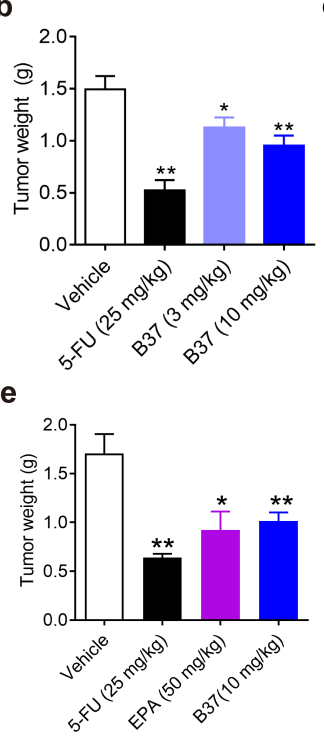

g

(1342) h

(1292) (1170)

(1391) (1349)

(F270) ( 1346 F214) -

( 3433

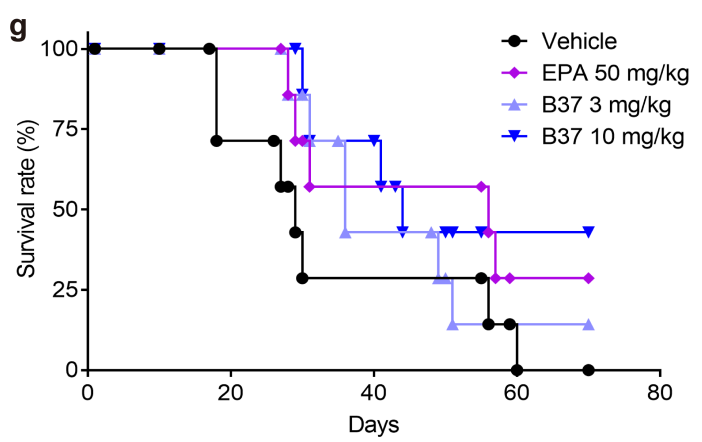



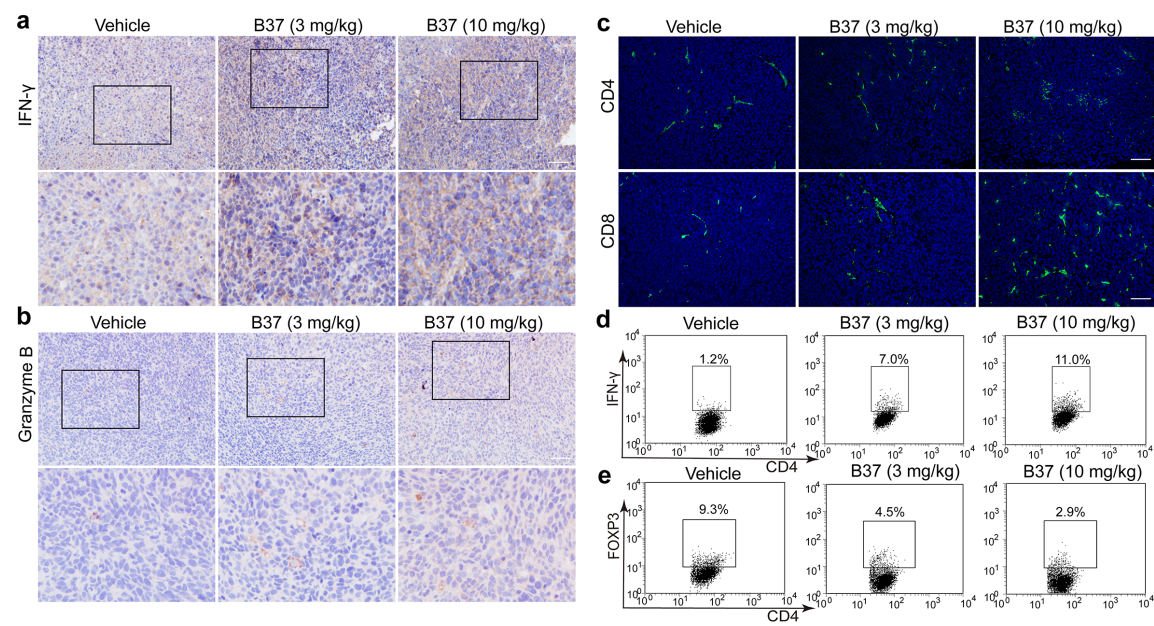

a
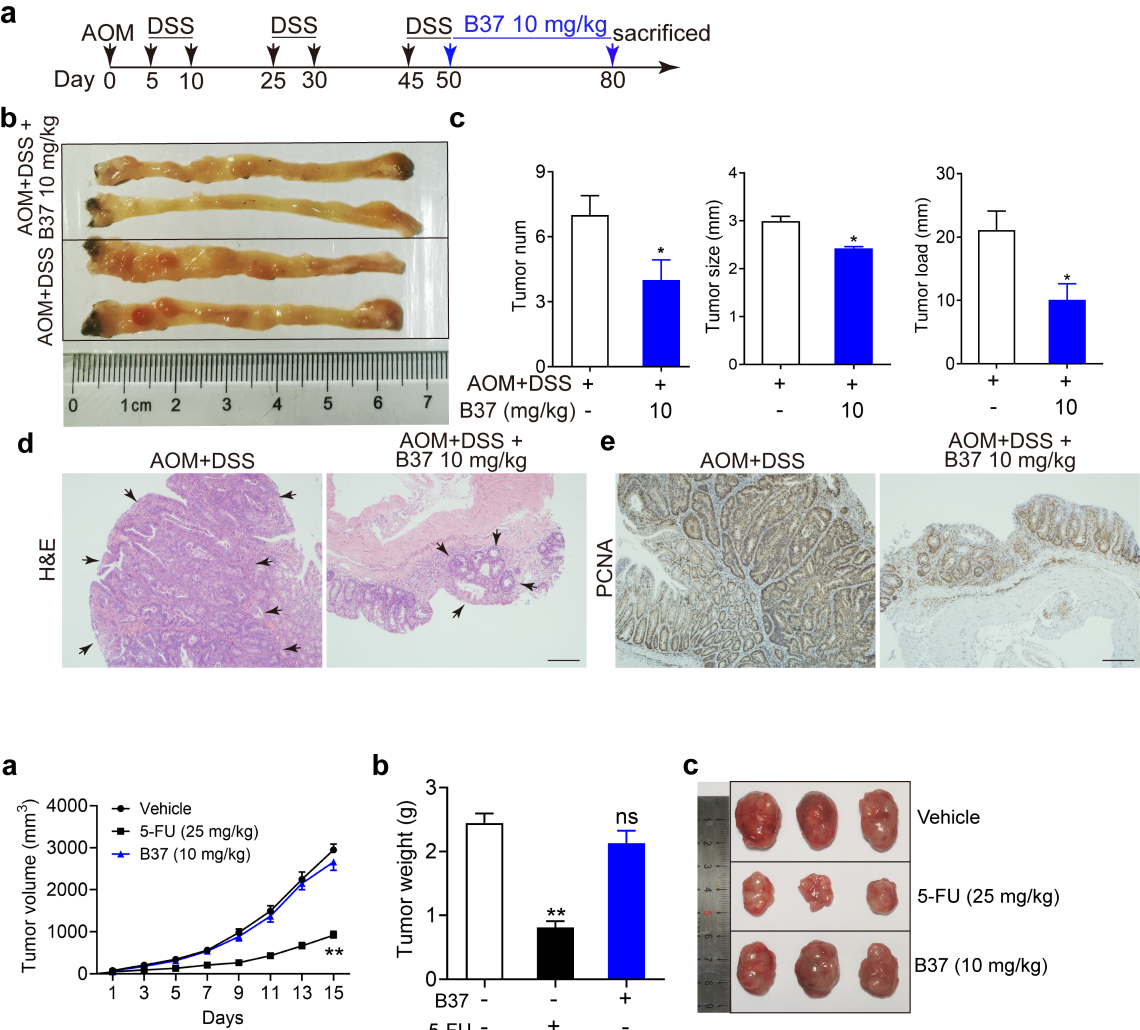

b
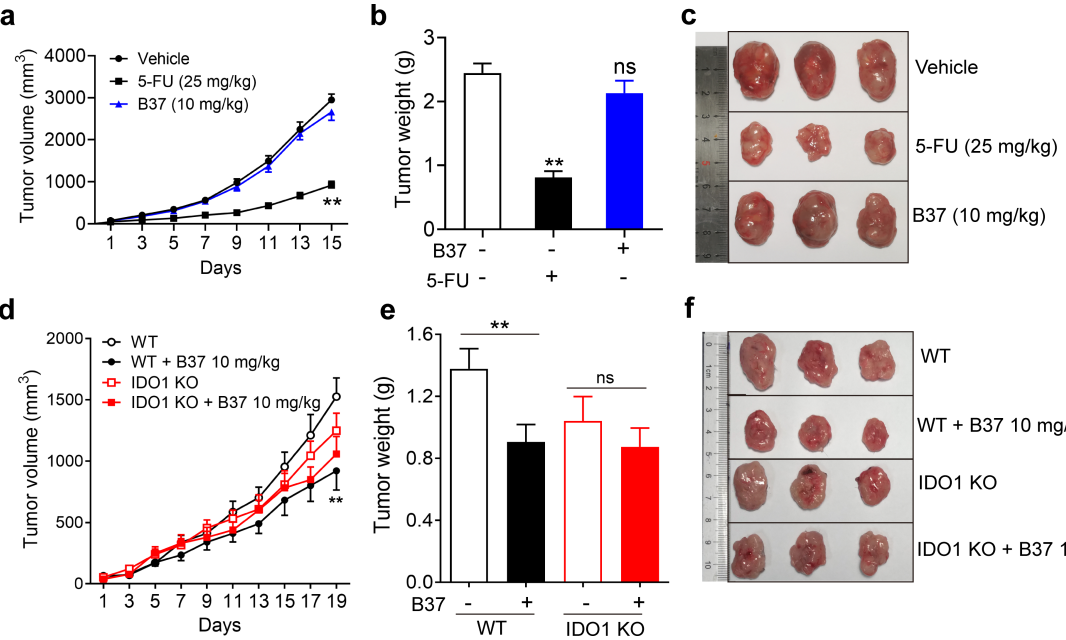

e
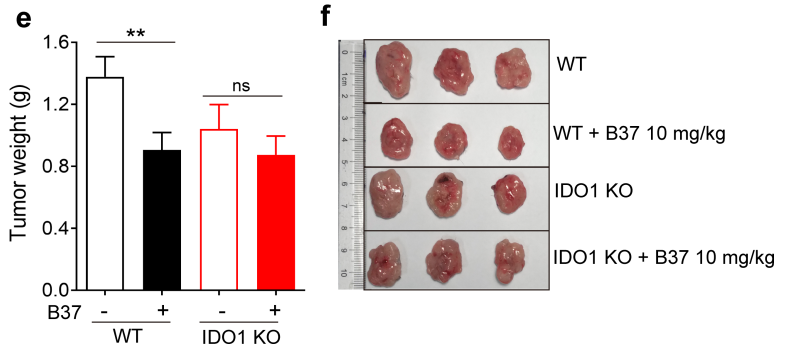
a

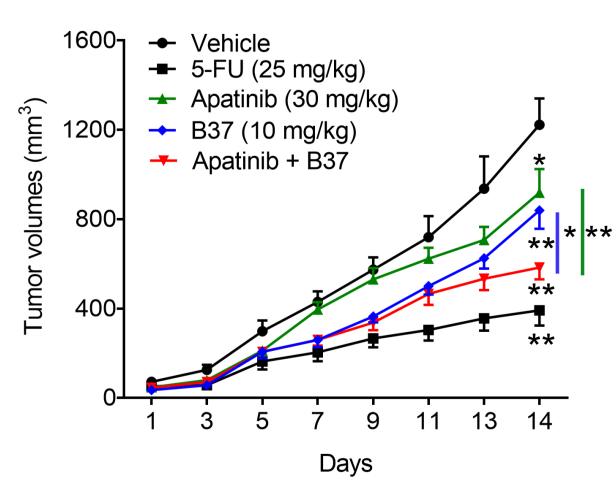

b

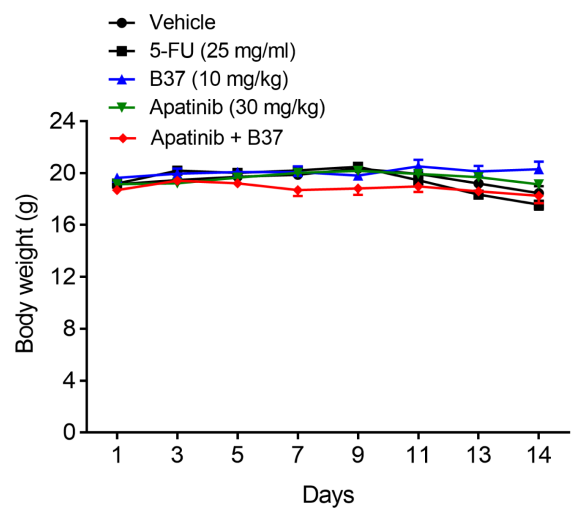

C

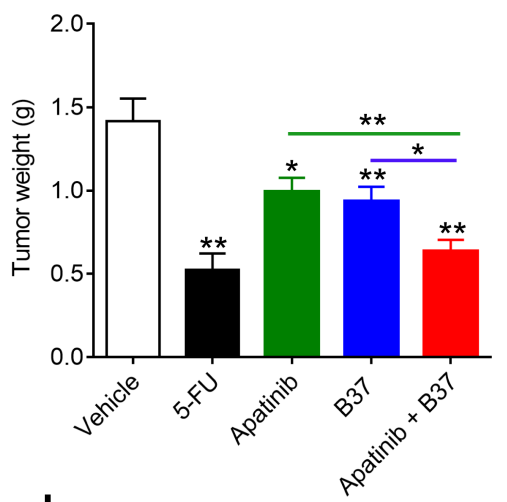

d

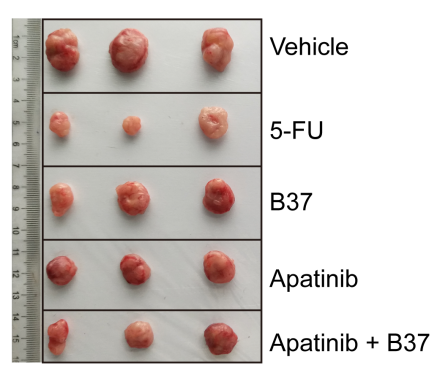

